\title{
Sex differences in pharmacokinetics predict adverse drug reactions in women
}

Irving Zucker ${ }^{1,2^{*}}$ (D) and Brian J. Prendergast ${ }^{3}$

\begin{abstract}
Background: Women experience adverse drug reactions, ADRs, nearly twice as often as men, yet the role of sex as a biological factor in the generation of ADRs is poorly understood. Most drugs currently in use were approved based on clinical trials conducted on men, so women may be overmedicated. We determined whether sex differences in drug pharmacokinetics, PKs, predict sex differences in ADRs.

Methods: Searches of the ISI Web of Science and PubMed databases were conducted with combinations of the terms: drugs, sex or gender, pharmacokinetics, pharmacodynamics, drug safety, drug dose, and adverse drug reaction, which yielded over 5000 articles with considerable overlap. We obtained information from each relevant article on significant sex differences in PK measures, predominantly area under the curve, peak/maximum concentrations, and clearance/elimination rates. ADRs were identified from every relevant article and recorded categorically as female-biased, male-biased, or not sex-biased.
\end{abstract}

Results: For most of the FDA-approved drugs examined, elevated blood concentrations and longer elimination times were manifested by women, and these PKs were strongly linked to sex differences in ADRs. Of the 86 drugs evaluated, 76 had higher PK values in women; for 59 drugs with clinically identifiable ADRs, sex-biased PKs predicted the direction of sex-biased ADRs in $88 \%$ of cases. Ninety-six percent of drugs with female-biased PK values were associated with a higher incidence of ADRs in women than men, but only 29\% of male-biased PKs predicted male-biased ADRs. Accessible PK information is available for only a small fraction of all drugs

Conclusions: Sex differences in pharmacokinetics strongly predict sex-specific ADRs for women but not men. This sex difference was not explained by sex differences in body weight. The absence of sex-stratified PK information in public records for hundreds of drugs raises the concern that sex differences in PK values are widespread and of clinical significance. The common practice of prescribing equal drug doses to women and men neglects sex differences in pharmacokinetics and dimorphisms in body weight, risks overmedication of women, and contributes to female-biased adverse drug reactions. We recommend evidence-based dose reductions for women to counteract this sex bias.

Keywords: Sex differences, Drugs, Adverse drug reactions, Pharmacokinetics

\footnotetext{
* Correspondence: irvzuck@berkeley.edu

This article is dedicated to Stephen E. Glickman, 1933-2020.

'Department of Psychology, University of California, Berkeley, 2121 Berkeley

Way West, Berkeley, CA 94720, USA

${ }^{2}$ Department of Integrative Biology, University of California, Berkeley, 3040

VLSB, Berkeley, CA 94720, USA

Full list of author information is available at the end of the article
}

(c) The Author(s). 2020 Open Access This article is licensed under a Creative Commons Attribution 4.0 International License, which permits use, sharing, adaptation, distribution and reproduction in any medium or format, as long as you give appropriate credit to the original author(s) and the source, provide a link to the Creative Commons licence, and indicate if changes were made. The images or other third party material in this article are included in the article's Creative Commons licence, unless indicated otherwise in a credit line to the material. If material is not included in the article's Creative Commons licence and your intended use is not permitted by statutory regulation or exceeds the permitted use, you will need to obtain permission directly from the copyright holder. To view a copy of this licence, visit http://creativecommons.org/licenses/by/4.0/. The Creative Commons Public Domain Dedication waiver (http://creativecommons.org/publicdomain/zero/1.0/) applies to the data made available in this article, unless otherwise stated in a credit line to the data. 


\section{Introduction}

Women historically were excluded from clinical pharmaceutical trials because of potential risks to individuals of childbearing potential. The now discredited belief that studies of men apply without modification to women also contributed to this oversight. Remediation by the US National Institute of Health (NIH) Revitalization Act of 1993 mandated enrollment of women in federally supported phase III clinical trials; a European Union initiative provided practical tools regarding sex differences in drug study design [1]. Although the inclusion of women in clinical research subsequently increased in the USA, the EU, and Australia [1-4], most studies did not provide sexspecific data analyses [5, 6]. A 2018 review of $107 \mathrm{NIH}$ funded randomized control trial studies that enrolled both men and women found that only $26 \%$ reported even one outcome by sex or included both sexes as a covariate [7]; $72 \%$ simply did not include sex in their analyses. NIH policies mandated over a quarter century ago have yet to yield the intended increases in reporting by sex.

A consequence of this sex inequality hides in plain sight today: most drugs are prescribed to women and men at the same dose. Many currently prescribed drugs were approved by the US Food and Drug Administration (FDA) prior to 1993, with inadequate enrollment of female animals in preclinical research and of women in clinical trials [8]. An illustrative example is found in the sedative-hypnotic drug zolpidem, which has been marketed under several names (e.g., Ambien, Edluar, Zolpimist) since it was first approved by the FDA, 1 year before the NIH Revitalization Act. Only after decades of post-marketing reports of cognitive deficits in women given the standard male dose were sex-based dose adjustments developed (NDA 021774). Many other drugs administered in equal doses to women and men likely require re-evaluation for sex-specific dose adjustment. Even within sex, dosing is not usually weight-adjusted in adults [9]; it remains uncertain whether weight-adjusted doses will suffice to offset the majority of sex-specific ADRs. One survey of clinical pharmacology data for 300 new drug applications (NDAs) evaluated by the FDA between 1994 and 2000 [10] indicated that $31 \%$ of studies showed a possible sex effect based on pharmacokinetic (PK) sex differences greater than $20 \%$. In the same report, 11 drugs showed a $>40 \%$ difference between males and females in PK measures, yet no dosing recommendations to consider sex were issued, implicitly based on the unsubstantiated grounds that these differences were not clinically relevant. The existing knowledge base for sex-aware prescribing lacks information on sex differences for one-third of all drugs [9, 10]. Pharmaceutical companies responsible for generating pre-approval data often fail to include information on sex differences in NDA documents, and the FDA has previously failed to enforce its own requirements before approving new drugs [11]. Consequently, potential sex differences in PK measures and their relation to unwanted side effects often remain unknown. Most of the data submitted to the FDA by drug companies are not publicly available and not subject to peer-review by the broader scientific community [9]. Regulatory agencies have historically paid insufficient attention to differences between women and men in terms of both sex and gender, which perpetuates inequalities by neglecting drug safety problems that are sex-specific. In addition, this disparity allows for misleading drug marketing [11].

The present review study inventories drugs that elicit different responses in women and men and considers sex differences in adverse drug reactions (ADRs) that occur in individuals treated with therapeutic doses of medications. The range of ADRs included, but was not limited to, nausea, headache, drowsiness, depression, excessive weight gain, cognitive deficits, seizures, hallucinations, agitation, and cardiac anomalies. Sex differentiated ADRs were operationally defined as statistically significant differences in unintended drug effects in one sex, as reported in peer-reviewed literature or in NDAs. Supplementary evidence of ADRs was obtained from VigiBase [12], the World Health Organization (WHO) global database of individual case safety reports (ICSRs), which since 1968 has aggregated ICSRs from member countries of the WHO Programme for International Drug Monitoring. It is important to note that pharmacovigilance datasets, including but not limited to VigiBase, have a number of shortcomings: the information in VigiBase comes from a variety of sources, and the probability that the suspected ADR is, in fact, drug-related is not the same in all cases. Thus, it cannot be proven that a specific drug caused an ADR, rather than an underlying illness or other concomitant medication. Reports submitted to VigiBase come from both regulated and voluntary sources, and the volume of reports about a given substance may be influenced by extent of use of the product, the nature of the ADR, and/or publicity. Lastly, many drugs are disproportionately prescribed to one sex, and VigiBase data do not account for the number of patients of each sex exposed to the drug [13].

In contrast, much stronger and less confounded evidence comes from clinical trials and experimentally controlled empirical studies of drugs, in which ADRs can be quantified in the context of a known number of subjects administered the drug. Because the present report is, to our knowledge, the most comprehensive attempt yet to identify sex-biased ADRs using clinically identified ADR data, it also provided an opportunity to evaluate the accuracy of VigiBase data in estimating sex differences in ADRs compared to estimates obtained under more controlled experimental conditions. 


\section{Reasons why men and women respond differently to drugs}

Women have a nearly 2-fold greater risk than men for exhibiting ADRs across all drug classes and are significantly more likely to be hospitalized secondary to an ADR [14-16]. This disparity is pervasive: among 668 drugs of the 20 most frequent treatment regimens in the USA, 307 (46\%) report significant sex differences in ADRs [17]. In an analysis of cohort studies on 48 drugs completed between 1982 and 1997, compiling data from > 500,000 patients, Martin et al. [18] concluded that women over the age of 19 were 43 to $69 \%$ more likely to have an ADR recorded by their general practitioner. ADRs also peaked earlier in development among women (30-39 years of age) than men (50-59 years of age [18];). Women are also more likely than men to use two or more medications concurrently (polypharmacy), and women use more unique medications per year (5.0 vs. 3.7 , respectively), which may contribute to increased female ADRs [19] but also renders the issue of sex-aware dosing all the more critical.

A comprehensive survey of the chemical and biological processes that underlie PKs and pharmacodynamics (PDs), and sex differences therein, is beyond the scope of the present work. We refer the reader to several thorough reviews of mechanisms relevant to PKs and PDs $[20,21]$ and sex differences in drug disposition [22, 23]. Here we discuss biophysical and molecular mechanisms only as required for illustration. Future analyses of drug elimination mechanisms (e.g., via CYP3A4) may facilitate extrapolation of the present results to a larger sample of drugs.

In general, drug disposition occurs through separate phases: absorption, distribution, bioavailability, metabolism, and excretion, and sex differences have been documented for each phase $[22,23]$. Women generally have a lower body weight and organ size and a higher percentage of body fat, which affects the absorption and distribution of drugs. The larger the volume of distribution $\left(\mathrm{V}_{\mathrm{d}}\right)$, the more likely the drug will be found in body tissues.

A number of biological, psychological, and cultural factors may contribute to why sex is such a strong risk factors for ADRs, including the following: sex differences in PKs and PDs, sex-specific organizational (early life) and activational (peripubertal through adulthood) endogenous steroid hormone exposure, and sex differences in exogenously administered steroids, higher rates of polypharmacy in women, sex differences in the expression of somatoform disorders, and sex differences in reporting rates [24].

Drug clearance is strongly linked to sex-specific expression of metabolic enzyme systems [25-27]; renal clearance of drugs is decreased in women because of a relatively lower glomerular filtration rate compared to men [28]. Women have a slower gastric emptying time and lower gastric $\mathrm{pH}$, lower plasma volume, body mass index, average organ blood flow, and total body water differences, all of which affect drug distribution and PKs [29]. Responses to drugs are also affected by physiological changes during the menstrual cycle. The striking hormonal variations across days over the course of the human menstrual have no parallel in men in which hormonal variations largely occur within rather than across days [30].

The anticoagulant drug lepirudin is excreted by the kidney with systemic clearance in women about $25 \%$ lower than in men (NDA 020807 [31]). But PK variables do not translate linearly into phenotypes; thus, in women lepirudin is detectible in the circulation for up to $48 \mathrm{~h}$, compared to just $2 \mathrm{~h}$ in men, which greatly increases the potential for undesired bleeding [32]; indeed, in this example, low molecular weight heparin-induced thrombocytopenia is a clinically important ADR which occurs more frequently in women than men [33], a difference that corresponded to much higher drug exposure as indicated by female-bias in multiple PK measures.

Arpon et al. [34] maintain that dosing adjusted according to a range of patient-specific factors is of large and increasing clinical and financial concern but lament that the amount of body weight adjusted dosing change that occurs in clinical practice is presently unknown. Adjustments for body mass in most cases do not ameliorate the high incidence of female ADRs. Thus, a multivariate regression analysis controlling for age, body mass index, and number of prescribed drugs identified a strong and significant effect of female sex on the increased risk of encountering ADRs, indicating that the sex disparity in ADRs does not merely reflect body mass masquerading as an effect of sex [35].

Most drugs are not administered on a milligram/kilogram basis but as a "one size fits all" dose, leading to higher exposures in women [10]. Under optimal circumstances, the dose should be based on milligram/kilogram body weight, or titrated to the desired clinical effect [36]. Correction for height, weight, surface area, or body composition eliminates a minority of sex-dependent PK differences [10]. The inference that weight-corrected PKs are comparable between men and women is not generally warranted but must be examined on a case-by-case basis, if data on both sexes exist. If for a given drug with a sexually differentiated pattern of ADR expression, correction for body weight eliminates the sex differences in PKs, this may or may not have bearing on PK-driven exposure leading to sex-differentiated ADRs. In short, sex differences in PK may be sufficient but not necessary for the manifestation of sex differences in ADRs.

PKs differ in men and women for many drugs [4, 2123, 37-40]; this impacts drug efficacy and toxicity [41, 42]. Data from bioequivalence trials identified significant 
sex differences in PKs in 28\% of data sets [43]. Despite these differences, sex-specific dosing recommendations are absent for most drugs [37]. When women consistently experience less therapeutic effect or more adverse effects, a change in dosing regimen may be necessary.

Sex-related differences in PKs present a more significant challenge for medications with a low therapeutic index, i.e., those in which the lowest effective dose approaches toxic concentrations $[44,45]$. If the therapeutic index is narrow, these differences are more likely to become clinically significant. A detailed study of sex differences for drugs with either steep dose response curves or narrow therapeutic indices is warranted [46]. For drugs with a relatively wide therapeutic index, a fixed dosing regimen is less of an impediment, but even in these instances, selecting the lowest effective dose would be prudent in women, at a minimum to decrease the potential for ADRs, as women are more likely than men to be prescribed more than one drug at a time.

Population PK studies often rely on sparse blood sampling collected from many subjects in phase II and III clinical trials. PK information is included in only a small minority of approved drug labels [10]; among > 2500 compounds listed in the Physicians Desk Reference (PDR), only 88 (fewer than $4 \%$ ) presented population PK information in labelling [47]. PK sex difference data routinely are derived from small clinical pharmacology studies, typically enrolling 12-24 healthy subjects. Studies with such relatively small sample sizes have lower statistical power: they may be adequate to detect only very large sex differences in PK attributes, but as effect sizes decrease, these underpowered experimental designs generate widespread type II statistical errors-they become less and less capable of identifying real sex differences.

\section{Aims}

Here we examine relations between sex differences in drug PKs and ADRs to critically evaluate the hypothesis that drug exposure (PKs) and bodily responses to drugs (PDs; more specifically, clinically unintended effects, or ADRs) should be considered in the development of rational, feasible sex-based dosing adjustments. We conclude that such considerations are presently missing and recommend that sex-based dosing recommendations be disseminated to physicians and appear on drug labels. In many cases, these changes can be implemented at little cost. As demonstrated below, the data required to implement these procedures already exist for a number of drugs but have been ignored.

To determine the extent to which sex as a biological variable has been incorporated in the development of therapeutic pharmaceuticals, we reviewed whether sex differences in PK data were identified for any given drug and, where present, if such differences were incorporated into recommendations for sex-aware dosing/prescribing. Additionally, we reviewed an extensive literature on sexspecific ADRs, to evaluate whether sex differences in PK data predict sex disparities in ADRs. The hypothesis tested was that sex differences in PKs, specifically higher drug exposure in women than men, would be associated with clinically significant sex differences in ADRs. Support for this hypothesis, based on the broad net cast in the present investigation, would support dose reductions in women for the drugs under investigation here, and perhaps warrant extrapolation to any drugs for which sex differences in PKs exist. Several recent comprehensive reviews have addressed sex differences in drug treatment targeting specific diseases [48-53]. Here we report, for the first time, substantial sex differences in PKs and ADRs for 86 drugs, spanning multiple ( $>10)$ therapeutic categories that support dose adjustments for women.

\section{Methods}

\section{Objective}

To examine whether sex differences in PKs are related to sex differences in ADRs, we reviewed empirical studies that measured PKs in females and males treated with FDA-approved drugs and quantitative reports documenting ADRs in both sexes.

\section{Search strategy, analysis steps, and criteria for study inclusion}

Multiple searches of the ISI Web of Science database (core collection, basic search; Thompson Scientific) were conducted throughout 2018-19 with the terms: drugs and sex differences and pharmacokinetics (848 articles), drugs and gender and pharmacokinetics (1548 articles), drugs and sex differences and pharmacodynamics (385 articles), drug safety and dose and sex (651 article), drug safety and dose and gender (462 articles), adverse drug reactions and sex (912 articles), adverse drug reaction and gender (687 articles), which yielded 5493 articles, with considerable overlap. All years were included in the Web of Science and Pub Med searches. Only English language articles were accessed. For a publication to be included in the survey, it had to contain data on sex differences in pharmacokinetics and/or adverse drug responses. The Thompson Reuters Web of Science and the NCBI PubMed databases were searched with no date restrictions; the last search was completed in January 2020. The WHO's VigiBase database was searched with no date or geographic restrictions. 


\section{Data extraction}

PK measures Each article was examined for relevance with additional searches conducted in PubMed and Web of Science for specific drugs; relevant publications identified in target articles were also inspected. Many drugs do not have a sex bias in pharmacokinetics. In an unknown number of instances, this reflects a true absence of sex differences based on empirical findings. For many drugs, however, the available PK data are lacking because female subjects were either not included in study design, or data were not reported by sex. Only studies of drugs that have a sex bias in pharmacokinetics were considered. Risk bias was examined in all articles to determine whether both sexes were included, whether sample size was adequate, and if subjects enrolled were adults or children. Sample size was considered adequate if there were 10-12 subjects/group. Several articles reporting statistically significant results with smaller sample sizes were reported but flagged with a disclaimer. From each relevant article, data on sex differences in PK measures was extracted; the majority of these measures were in units of either area under the curve [AUC] or peak/maximum concentration $\left[C_{\max }\right]$; less frequently, data were available for drug half-life $\left[t_{1 / 2}\right]$, clearance/ elimination measures conducted over fixed time intervals, systemic exposure, $V_{d}$, and $T_{\max }$.

ADR measures ADRs were identified from every relevant article and recorded categorically as female-biased or male-biased. The EU database of ADR reports and the WHO's ADR monitoring website, also known as VigiBase, were searched. ADR data from this site are listed in instances where we were unable to find primary reports of ADRs for a specific drug. The ratio of women: men reporting ADRs was computed, and a value that deviated by more than $20 \%$ from 1.0 in either direction indicated that VigiBase reports were sex biased: values > 1.2 and $<0.80$ indicated female and male sex biases, respectively. Values between $0.80-1.20$ (inclusive) were interpreted as indicating no sex bias in ADRs. As discussed above, a major limitation of VigiBase is that it does not account for differences in the frequency with which women and men are treated with a specific drug. To directly examine this limitation in the context of sex differences in ADRs, we separately compared the prevalence of clinical ADRs (from data in the literature) with sex-specific reporting rates in VigiBase.

Label information and PK and PD data, where available, were obtained from the Drugs@FDA database [54]. Only data from human subjects were considered. Recreational drugs including alcohol, cocaine, nicotine, heroin, most psychedelics, and drugs involved in treatment of AIDS were beyond the scope of this review. For each drug, we report information published in peer-reviewed journals, from FDA NDA forms, and approved product labels. PK data are presented first, followed by ADRs.

Generally, sex differences refer to differences between women and men in the gonads, genitals, hormones, chromosome, and gene complements. Gender differences are more difficult to define and usually encompass gender roles and gender identity. With a few exceptions, we use the term sex differences to describe differences in pharmacokinetics, pharmacodynamics, and adverse drug reactions.

\section{Data reduction}

Results are provided in the form of a descriptive analyses of whether studies with sex-specific patterns of PK bias predict sex-specific patterns of ADR bias. Only studies with clear sex differences in pharmacokinetics were included in the data synthesis. Chi-square analyses also evaluated whether PK biases predicted VigiBase data.

Among the 86 drugs that were identified as having sex-specific PK data, one compound, tirilazad (ATC code N07XX01), exhibited clear sex-biased PK values (greater exposure in men), but neither clinical ADRs nor sufficient entries in VigiBase existed; as a result, tirilizad is discussed below but not included in final tabular calculations. Another drug, theophylline (R03DA04), exhibited conflicting PK data (i.e., some PK measures indicated greater exposure in women whereas others indicated greater exposure in men), no experimentally identified ADRs, but clear sex-biased adverse responses in post marketing reports and is therefore included in both the discussion and tabular calculations below. Lastly, for 4 drugs (mirabegron, sertraline, aspirin, and clozapine), ADRs were not uniformly present in one sex. For mirabegron, a number of publications indicated a female bias in ADRs, and for aspirin and sertraline, the overall number of ADRs reported was greater for women; these drugs were classified as having femalebiased ADRs. For clozapine, empirical reports and metaanalyses identified over a dozen sexually differentiated ADRs, but overall, more ADRs occurred in men than in women, so clozapine was classified as having a malebiased ADR profile.

\section{Results}

Data for all drugs are contained in Additional file 1 which lists sex-specific PKs for drugs from every individual report. Full information is included in this file narrative, along with measures of central tendency (mean, median) and variance (SD, SEM, range) from the original reports where available. These results are summarized in Tables 1, 2, and 3, which list the specific PK measures for each drug, their direction of sex bias, whether ADRs were female- or male-biased, and whether PK findings and ADR data were sex-concordant or sex-discordant. 
Table 1 Summary of sex-biased PK measures and concordance with clinical ADRs

\begin{tabular}{|c|c|c|c|c|c|}
\hline WHO ATC category & Drug $^{a}$ & $\begin{array}{l}\text { PK } \\
\text { measure }^{b}\end{array}$ & Female-biased ADRs & Male-biased ADRs & PK vs ADR \\
\hline \multirow{3}{*}{$\begin{array}{l}\text { Alimentary tract, } \\
\text { metabolism }\end{array}$} & Liraglutide & $\mathrm{CL}_{\mathrm{T}}$ & headache, vomiting, nausea & -- & Concordant \\
\hline & Ranitidine & $\begin{array}{l}A U C, \\
\mathrm{~T}_{\max }\end{array}$ & -- & Duodenal damage & Concordant \\
\hline & Rosiglitazone & $\mathrm{CL}_{\mathrm{T}}$ & Fracture & -- & Concordant \\
\hline \multirow[t]{5}{*}{$\begin{array}{l}\text { Blood and blood } \\
\text { forming organs }\end{array}$} & Heparin & $\mathrm{CL}_{\mathrm{T}}$ & $\begin{array}{l}\text { blood disorders, lymphatic } \\
\text { disorders, bleeding (60 yoa) }\end{array}$ & -- & Concordant \\
\hline & Aspirin & $\begin{array}{l}A \cup C, C I_{T} \\
t_{1 / 2}\end{array}$ & $\begin{array}{l}\text { elevated fibrinogen, CVD in } \\
\text { T2D }\end{array}$ & Bleeding & Concordant \\
\hline & Warfarin & $\mathrm{CL}_{\mathrm{T}}$ & Bleeding & -- & Concordant \\
\hline & Clopidogrel & $\begin{array}{l}\text { AUC, } \\
C_{\max }\end{array}$ & $\begin{array}{l}\text { fracture, bleeding, Gl } \\
\text { symptoms, IBD }\end{array}$ & -- & Concordant \\
\hline & Dabigatran & $A \cup C$ & Bleeding & -- & Concordant \\
\hline \multirow[t]{9}{*}{$\begin{array}{l}\text { Cardiovascular } \\
\text { system }\end{array}$} & Torasemide & $\begin{array}{l}\text { AUC, } \\
\mathrm{C}_{\max } \mathrm{Cl}_{\mathrm{T}} \\
\mathrm{t}_{1 / 2}\end{array}$ & Hospitalization & -- & Concordant \\
\hline & Pravastatin & $\begin{array}{l}\text { AUC, } \\
C_{\max }\end{array}$ & $\mathrm{CHD}$ & -- & Concordant \\
\hline & Amlodipine & $\mathrm{CL}_{\mathrm{T}}$ & Edema, flushing, palpitations & -- & Discordant \\
\hline & Digoxin & $\mathrm{CL}_{\mathrm{T}}$ & Mortality & -- & Concordant \\
\hline & Verapamil & $\mathrm{CL}_{\mathrm{T}}$ & $\begin{array}{l}\text { Constipation, edema, fatigue, } \\
\text { headache }\end{array}$ & -- & Concordant \\
\hline & Aliskiren & $\begin{array}{l}A \cup C \\
C_{\max }\end{array}$ & Diarrhea & -- & Concordant \\
\hline & Losartan & $\begin{array}{l}\text { AUC, } \\
C_{\max }\end{array}$ & -- & Angina, mortality & Discordant \\
\hline & Propranolol & $\begin{array}{l}A \cup C, \\
\mathrm{C}_{\max ,} \mathrm{Cl}_{\mathrm{T}}\end{array}$ & $\begin{array}{l}\text { dizziness muscle pain } \\
\text { headache dry mouth }\end{array}$ & -- & Concordant \\
\hline & Dofetilide & SysExp & $\mathrm{TdP}$ & -- & Concordant \\
\hline \multirow[t]{3}{*}{$\begin{array}{l}\text { Genito-urinary } \\
\text { system, sex } \\
\text { hormones }\end{array}$} & Mirabegron & $\begin{array}{l}\text { AUC, } \\
C_{\max } \\
\text { SysExp }\end{array}$ & $\begin{array}{l}\text { Treatment discontinuation } \\
\text { (CAN), treatment } \\
\text { discontinuation (CZE) }\end{array}$ & Treatment discontinuation (UK) & Concordant \\
\hline & Darifenacin & $\begin{array}{l}\text { AUC, } \\
\mathrm{C}_{\max } \mathrm{Cl}_{\mathrm{T}}\end{array}$ & $F>M$, ADRs not specified & -- & Concordant \\
\hline & Trospium & $\begin{array}{l}\text { AUC, } \\
C_{\max }\end{array}$ & Cognitive impairments & -- & Concordant \\
\hline $\begin{array}{l}\text { Systemic hormonal } \\
\text { preparations }\end{array}$ & Prednisone & $A \cup C, C_{T}$ & $\begin{array}{l}\text { Depression, fatigue, hair loss, } \\
\text { mood swings, weight gain }\end{array}$ & -- & Concordant \\
\hline \multirow[t]{3}{*}{ Anti-infectives } & Levofloxacin & $\begin{array}{l}\mathrm{Cl}_{\mathrm{T}} \\
\text { SysExp }\end{array}$ & Fluoroquinolone toxicity & -- & Concordant \\
\hline & Erythromycin & $\mathrm{CL}_{\mathrm{T}}$ & $\mathrm{TdP}$ & -- & Discordant \\
\hline & Voriconazole & $\begin{array}{l}\text { AUC, } \\
C_{\max }\end{array}$ & cardiac QTc symptoms & -- & Concordant \\
\hline \multirow{6}{*}{$\begin{array}{l}\text { Antineoplastics, } \\
\text { immunomodulators }\end{array}$} & Cyclosporin & $\mathrm{CL}_{\mathrm{T}}$ & -- & -- & Discordant* \\
\hline & Fluorouracil & $A \cup C, C_{T}$ & $\begin{array}{l}\text { Stomatitis, leukopenia, } \\
\text { alopecia, diarrhea, mucositis }\end{array}$ & -- & Concordant \\
\hline & Paclitaxel & $\mathrm{CL}_{\mathrm{T}}$ & $\begin{array}{l}\text { Myocardial infarction, death, } \\
\text { lesion revascularization }\end{array}$ & -- & Concordant \\
\hline & Capecitabine & $A \cup C$ & Dose-limiting toxicity & -- & Concordant \\
\hline & Infliximab & $\mathrm{CL}_{\mathrm{T}}$ & Allergic reactions & -- & Concordant \\
\hline & Adalimumab & $\mathrm{CL}_{\mathrm{T}}$ & Allergic reactions & -- & Concordant \\
\hline Anesthetics, & Morphine & $\mathrm{CL}_{\mathrm{T}}$ & Respiratory depression, & -- & Concordant \\
\hline
\end{tabular}


Table 1 Summary of sex-biased PK measures and concordance with clinical ADRs (Continued)

\begin{tabular}{|c|c|c|c|c|c|}
\hline WHO ATC category & Drug $^{a}$ & $\begin{array}{l}\text { PK } \\
\text { measure }^{b}\end{array}$ & Female-biased ADRs & Male-biased ADRs & PK vs ADR \\
\hline \multirow[t]{6}{*}{ analgesics } & & & $\begin{array}{l}\text { hypoxic sensitivity, emesis, } \\
\text { nausea }\end{array}$ & & \\
\hline & Oxycodone & $\mathrm{CL}_{\mathrm{T}}$ & $\begin{array}{l}\text { Nausea, pruritus, negative } \\
\text { affect }\end{array}$ & -- & Concordant \\
\hline & Buprenorphine & $\begin{array}{l}\text { AUC, } \\
C_{\max }\end{array}$ & Sleep disturbance & -- & Concordant \\
\hline & Tramadol & $\begin{array}{l}A \cup C \\
C_{\max }\end{array}$ & Treatment discontinuation & -- & Concordant \\
\hline & Zolmitriptan & $\begin{array}{l}\text { AUC, } \\
C_{\max }\end{array}$ & Face and neck presure & -- & Concordant \\
\hline & Ketamine & $\mathrm{Cl}_{\mathrm{T}}$ & -- & Verbal learning, subjective memory & Concordant \\
\hline \multirow[t]{4}{*}{$\begin{array}{l}\text { Anti-epileptics, anti- } \\
\text { Parkinson's }\end{array}$} & Carbamazepine & $\mathrm{Cl}_{\mathrm{T}}, \mathrm{t}_{1 / 2}$ & $\begin{array}{l}\text { Cognitive impairment, } \\
\text { elevated LDL/HDL }\end{array}$ & -- & Discordant \\
\hline & Gabapentin & $C_{\max }$ & $\begin{array}{l}\text { Dizziness, somnolescence, } \\
\text { nausea }\end{array}$ & -- & Concordant \\
\hline & Perampanel & $A \cup C, C_{T}$ & $\begin{array}{l}\text { Dizziness, headache, treatment } \\
\text { discontinuation }\end{array}$ & -- & Concordant \\
\hline & Pramipexole & $\begin{array}{l}\text { AUC, } \\
C_{\max }\end{array}$ & Nausea, fatigue & -- & Concordant \\
\hline \multirow[t]{7}{*}{ Psycholeptics } & Olanzapine & $\mathrm{CL}_{\mathrm{T}}$ & Severe weight gain & & Concordant \\
\hline & Clozapine & $\mathrm{CL}_{\mathrm{T}}$ & $\begin{array}{l}\text { Blood glucose, laxative use, } \\
\text { obesity, type II diabetes, } \\
\text { neutropenia, leukopenia, } \\
\text { weight gain }\end{array}$ & $\begin{array}{l}\text { Hypertension, increases in BMI, elevated } \\
\text { homocysteine, increased basal metabolic rate, } \\
\text { increased plasma lipids, QTc symptoms, blood } \\
\text { dyscrasias, myocarditis, cardiomyopathy }\end{array}$ & Discordant \\
\hline & Risperidone & $\mathrm{CL}_{\mathrm{T}}$ & $\begin{array}{l}\text { Hyperprolactinemia, } \\
\text { neurological effects, headache, } \\
\text { hypotension }\end{array}$ & - & Concordant \\
\hline & Aripiprazol & $\begin{array}{l}\text { AUC, } \\
C_{\max }\end{array}$ & $\begin{array}{l}\text { Blood pressure, heart rate, } \\
\text { elongated QTC }\end{array}$ & -- & Concordant \\
\hline & Diazepam & $t_{1 / 2}$ & Psychomotor impairment & -- & Concordant \\
\hline & Zolpidem & $\begin{array}{l}A \cup C, \\
C_{\text {max }} C_{T}\end{array}$ & $\begin{array}{l}\text { Cognitive impairment, driving } \\
\text { impairment }\end{array}$ & -- & Concordant \\
\hline & Eszopiclone & $A \cup C$ & Dysgeusia & -- & Concordant \\
\hline \multirow[t]{7}{*}{ Psychoanaleptics } & Imipramine & $\mathrm{CL}_{\mathrm{T}}$ & $\begin{array}{l}\text { Dry mouth, constipation, } \\
\text { sweating, tremor, treatment } \\
\text { discontinuation }\end{array}$ & -- & Concordant \\
\hline & Nortriptyline & $\mathrm{CL}_{\mathrm{T}}$ & Dry mouth & -- & Concordant \\
\hline & Fluoxetine & $\mathrm{CL}_{\mathrm{T}}$ & $\begin{array}{l}\text { Hypercortisolemia, elevated } \\
\text { albumin, elevated tryptophan, } \\
\text { suicidal ideation }\end{array}$ & -- & Concordant \\
\hline & Citalopram & $\mathrm{CL}_{\mathrm{T}}$ & Elevated ADH & -- & Concordant \\
\hline & Sertraline & $\begin{array}{l}A \cup C, C I_{T} \\
t_{1 / 2}\end{array}$ & $\begin{array}{l}\text { Cholesterol, nausea, dizziness, } \\
\text { delusions }\end{array}$ & $\begin{array}{l}\text { Dyspepsia, sexual dysfunction, urinary } \\
\text { frequency }\end{array}$ & Concordant \\
\hline & Bupropion & $\begin{array}{l}\text { AUC, } \\
C_{\text {max }}, t_{1 / 2}\end{array}$ & EEG abnormalities, seizure & -- & Concordant \\
\hline & Methylphenidate & $A \cup C$ & Anxiety disorder & -- & Discordant \\
\hline Antiparasitics & Primaquine & $\begin{array}{l}\text { AUC, } \\
C_{\max }\end{array}$ & Nausea & -- & Concordant \\
\hline \multirow[t]{2}{*}{ Respiratory } & Terfenadine & $C_{\max }$ & $\mathrm{TdP}$ & -- & Concordant \\
\hline & Fexofenadine & $\begin{array}{l}\text { AUC, } \\
C_{\max }\end{array}$ & $\begin{array}{l}\text { Visual attention deficits, } \\
\text { reaction time deficits, driving } \\
\text { impairments }\end{array}$ & -- & Concordant \\
\hline
\end{tabular}


Table 1 Summary of sex-biased PK measures and concordance with clinical ADRs (Continued)

\begin{tabular}{|c|c|c|c|c|c|}
\hline WHO ATC category & Drug $^{a}$ & $\begin{array}{l}\text { PK } \\
\text { measure }^{b}\end{array}$ & Female-biased ADRs & Male-biased ADRs & PK vs ADR \\
\hline \multirow[t]{2}{*}{ Miscellaneous } & MDMA & $\mathrm{CL}_{\mathrm{T}}$ & $\begin{array}{l}\text { Elevated copeptin, } \\
\text { hyponatremia }\end{array}$ & -- & Concordant \\
\hline & Cannabis & $\mathrm{CL}_{\mathrm{T}}$ & $\begin{array}{l}\text { Increased subjective emotional } \\
\text { responses, problematic } \\
\text { useintrovertive anhedonia }\end{array}$ & -- & Concordant \\
\hline
\end{tabular}

PK abbreviations: $A U C$ area under the curve, $C_{\max }$ maximum circulating concentration, $T_{\max }$ time required to reach $C_{\max }$ value, $t_{1 / 2}$ elimination half-life, $C l_{T}$ clearance time, exposure, or plasma concentration after a fixed time interval, SysExp systemic exposure

*No evidence of sex differences in ADRs

${ }^{a}$ Font style of drug name indicates direction of PK drug exposure bias: (normal font: $F>M$; bold font: $M>F$ )

${ }^{b}$ Font style of PK measure indicates direction of greater drug exposure (normal: $F>M$; bold: $M>F$ )

Table 2 Concordance between sex-biased PKs and VigiBase sex ratios

\begin{tabular}{|c|c|c|c|c|}
\hline WHO ATC category & Drug name/PK bias ${ }^{a}$ & PK measure ${ }^{b}$ & VB ratio $^{c}$ & Concordance \\
\hline Alimentary tract, metabolism & Ondansetron & $A \cup C, C_{\max }$ & 2.14 & Concordant \\
\hline Blood and blood forming organs & Icatibant & $A \cup C, C_{\max }$ & 3.18 & Concordant \\
\hline \multirow[t]{4}{*}{ Cardiovascular system } & Metoprolol & $A \cup C, C_{\max }$ & 1.26 & Concordant \\
\hline & Labetalol & $\mathrm{C}_{\text {max }} \mathrm{Cl}_{\mathrm{T}}$ & 1.50 & Concordant \\
\hline & Nifedipine & $\mathrm{Cl}_{\mathrm{T}}$ & 1.29 & Discordant ${ }^{1}$ \\
\hline & Pitavastatin & $A \cup C, C_{\max }$ & 1.12 & Discordant ${ }^{2}$ \\
\hline Systemic hormonal preparations & Methylprednisolone & $A U C, \mathrm{t}_{1 / 2}, \mathrm{Cl}_{\mathrm{T}}$ & 1.38 & Discordant ${ }^{1}$ \\
\hline Musculoskeletal & Ibuprofen & $A U C, \mathrm{C}_{\max }, \mathrm{t}_{1 / 2}, \mathrm{Cl}_{\mathrm{T}}$ & 1.46 & Discordant ${ }^{1}$ \\
\hline \multirow[t]{4}{*}{ Anesthetics, analgesics } & Lignocaine & $\mathrm{Cl}_{\mathrm{T}}$ & 1.64 & Condordant \\
\hline & Propofol & $A \cup C, \mathrm{Cl}_{\mathrm{T}}$ & 1.45 & Concordant \\
\hline & Butorphanol & $A \cup C, C_{\max }$ & 3.23 & Concordant \\
\hline & Paracetamol & $\mathrm{Cl}_{\mathrm{T}}$ & 1.68 & Concordant \\
\hline Anti-epileptics & Ezogabine & $A \cup C, C_{\max }, C l_{T}$ & 0.90 & Discordant $^{2}$ \\
\hline \multirow[t]{6}{*}{ Psycholeptics } & Clobazam & $t_{1 / 2}$ & 1.11 & Discordant $^{2}$ \\
\hline & Sertindole & $A \cup C, C_{\max }$ & 1.06 & Discordant $^{2}$ \\
\hline & Thiothixene & $\mathrm{Cl}_{\mathrm{T}}$ & 1.35 & Concordant \\
\hline & Oxazepam & $\mathrm{Cl}_{\mathrm{T}}$ & 1.31 & Concordant \\
\hline & Temazepam & $\mathrm{t}_{1 / 2}, \mathrm{Cl}_{\mathrm{T}}$ & 1.34 & Concordant \\
\hline & Zopiclone & $A \cup C, C_{\max }$ & 1.55 & Concordant \\
\hline \multirow[t]{6}{*}{ Psychoanaleptics } & Memantine & SysExp & 1.50 & Condordant \\
\hline & Desipramine & $A \cup C, C_{T}$ & 1.59 & Concordant \\
\hline & Clomipramine & $\mathrm{Cl}_{\mathrm{T}}$ & 1.57 & Concordant \\
\hline & Paroxetine & $\mathrm{Cl}_{\mathrm{T}}$ & 2.00 & Concordant \\
\hline & Fluvoxamine & $\mathrm{Cl}_{\mathrm{T}}$ & 1.73 & Concordant \\
\hline & Mirtazapine & $\mathrm{Cl}_{\mathrm{T}}$ & 1.53 & Concordant \\
\hline Respiratory & Cetirizine & $\mathrm{Cl}_{\mathrm{T}}$ & 1.76 & Concordant \\
\hline
\end{tabular}

PK abbreviations: AUC area under the curve, Cmax maximum circulating concentration, Tmax time required to reach $C$ max value, $t 1 / 2$ elimination half-life, $C I T$ clearance time, exposure, or plasma concentration after a fixed time interval, SysExp systemic exposure, DurAbs duration of absorption

${ }^{a}$ Font style of drug name indicates direction of PK drug exposure bias: (normal: $F>M$; bold: $M>F$ )

${ }^{b}$ Font style of PK measure indicates direction of greater PK drug exposure: (normal: F > M; bold: $\mathrm{M}>\mathrm{F}$; italic: inconsistent)

${ }^{\mathrm{C}} \mathrm{F}$-to-M reporting ratio of suspected ADRs. Threshold for designation of sex bias $= \pm 20 \%$

${ }^{1}$ False positive

${ }^{2}$ False negative 
Table 3 Sex ratios of adverse drug event reports in VigiBase among 59 drugs with sex-biased ADRs

\begin{tabular}{|c|c|c|c|c|}
\hline WHO ATC category & Drug name/PK bias ${ }^{\mathbf{a}}$ & ADR bias & VB ratio ${ }^{\mathbf{b}}$ & ADR-VB relation \\
\hline \multirow[t]{3}{*}{ Alimentary tract, metabolism } & Liraglutide & Females & 1.79 & Concordant \\
\hline & Ranitidine & Males & 1.52 & Discordant $^{1}$ \\
\hline & Rosiglitazone & Females & 0.79 & Discordant $^{1}$ \\
\hline \multirow[t]{5}{*}{ Blood and blood forming organ } & Heparin & Females & 0.92 & Discordant $^{2}$ \\
\hline & Aspirin & Females & 0.85 & Discordant $^{2}$ \\
\hline & Warfarin & Females & 0.91 & Discordant $^{2}$ \\
\hline & Clopidogrel & Females & 0.69 & Discordant $^{2}$ \\
\hline & Dabigatran & Females & 0.93 & Discordant $^{2}$ \\
\hline \multirow[t]{9}{*}{ Cardiovascular system } & Torasemide & Females & 1.15 & Discordant $^{2}$ \\
\hline & Pravastatin & Females & 1.13 & Discordant $^{2}$ \\
\hline & Amlodipine & Females & 1.41 & Concordant \\
\hline & Digoxin & Females & 1.26 & Concordant \\
\hline & Verapimil & Females & 1.56 & Concordant \\
\hline & Aliskiren & Females & 1.27 & Concordant \\
\hline & Losartan & Males & 1.41 & Discordant ${ }^{1}$ \\
\hline & Propranolol & Females & 1.72 & Concordant \\
\hline & Dofetilide & Females & 0.92 & Discordant $^{2}$ \\
\hline \multirow[t]{3}{*}{ Genito-urinary system, sex hormones } & Mirabegron & Females & 1.95 & Concordant \\
\hline & Darifenacin & Females & 2.48 & Concordant \\
\hline & Trospium & Females & 2.14 & Concordant \\
\hline Systemic hormonal preparations & Prednisone & Females & 1.17 & Discordant $^{2}$ \\
\hline \multirow[t]{3}{*}{ Anti-infectives } & Levofloxacin & Females & 1.26 & Concordant \\
\hline & Erythromycin & Females & 1.70 & Concordant \\
\hline & Voriconazole & Females & 0.65 & Discordant ${ }^{1}$ \\
\hline \multirow[t]{6}{*}{ Antineoplastics, immunomodulators } & Cyclosporin & Neither & 1.25 & Discordant ${ }^{1}$ \\
\hline & Fluorouracil & Females & 1.00 & Discordant $^{2}$ \\
\hline & Paclitaxel & Females & 2.66 & Concordant \\
\hline & Capecitabine & Females & 1.77 & Concordant \\
\hline & Infliximab & Females & 1.51 & Concordant \\
\hline & Adalimumab & Females & 2.02 & Concordant \\
\hline \multirow[t]{6}{*}{ Anesthetics, analgesics } & Morphine & Females & 1.57 & Concordant \\
\hline & Oxycodone & Females & 1.01 & Discordant $^{2}$ \\
\hline & Buprenorphine & Females & 1.61 & Concordant \\
\hline & Tramadol & Females & 1.71 & Concordant \\
\hline & Zolmitriptan & Females & 5.14 & Concordant \\
\hline & Ketamine & Males & 1.07 & Discordant $^{2}$ \\
\hline \multirow[t]{4}{*}{ Anti-epileptics, anti-Parkinson's } & Carbamazepine & Females & 1.26 & Concordant \\
\hline & Gabapentin & Females & 1.84 & Concordant \\
\hline & Perampanel & Females & 1.18 & Discordant $^{2}$ \\
\hline & Pramipexole & females & 1.19 & Discordant $^{2}$ \\
\hline \multirow[t]{4}{*}{ Psycholeptics } & Olanzapine & Females & 0.92 & Discordant $^{2}$ \\
\hline & Clozapine & Males & 0.61 & Concordant \\
\hline & Risperidone & Females & 0.53 & Discordant ${ }^{1}$ \\
\hline & Aripiprazol & Females & 1.27 & Concordant \\
\hline
\end{tabular}


Table 3 Sex ratios of adverse drug event reports in VigiBase among 59 drugs with sex-biased ADRs (Continued)

\begin{tabular}{|c|c|c|c|c|}
\hline WHO ATC category & Drug name/PK bias ${ }^{\mathbf{a}}$ & ADR bias & VB ratio ${ }^{\mathbf{b}}$ & ADR-VB relation \\
\hline & Diazepam & Females & 1.17 & Discordant $^{2}$ \\
\hline & Zolpidem & Females & 1.48 & Concordant \\
\hline & Eszopiclone & Females & 1.85 & Concordant \\
\hline \multirow[t]{7}{*}{ Psychoanaleptics } & Imipramine & Females & 1.61 & Concordant \\
\hline & Nortriptyline & Females & 2.10 & Concordant \\
\hline & Fluoxetine & Females & 2.29 & Concordant \\
\hline & Citalopram & Females & 1.95 & Concordant \\
\hline & Sertraline & Females & 2.00 & Concordant \\
\hline & Bupropion & Females & 1.79 & Concordant \\
\hline & Methylphenidate & Females & 0.47 & Discordant $^{1}$ \\
\hline Antiparasitics & Primaquine & Females & 0.55 & Discordant $^{1}$ \\
\hline \multirow[t]{2}{*}{ Respiratory } & Terfenadine & Females & 1.66 & Concordant \\
\hline & Fexofenadine & Females & 2.05 & Concordant \\
\hline \multirow[t]{2}{*}{ Miscellaneous } & MDMA & females & 0.43 & Discordant $^{1}$ \\
\hline & Cannabis & females & 0.51 & Discordant $^{1}$ \\
\hline
\end{tabular}

Threshold for designation of a VigiBase reporting sex bias was set at $\pm 20 \%$

${ }^{a}$ Font style of drug name indicates direction of PK drug exposure bias: (normal: $F>M$; bold: $M>F$ )

${ }^{b}$ Female-to-male (F:M) ratio of suspected ADRs

" "false sex" error

2"false null" error

We identified 86 drugs with significant sex differences in PKs, based on $\mathrm{C}_{\max }$ and $\mathrm{AUC}$ values or drug distribution and elimination rates. Many drugs with striking sex differences in ADRs did not make it onto this list because there were no available PK data, almost always because drugs were approved prior to the year 2000, and thus the relevant information is not available in the online FDA database.

The correspondence of sex differences in PKs with sex differences in ADRs was striking. In $88 \%$ of instances, a sex difference in PKs was linked to a similar sex difference in ADRs (52 of 59 drugs were PK-ADR "concordant," summarized in Table 1), a substantially higher incidence than the $46 \%$ sex difference in ADRs across all drugs assessed without regard to PK differences [17]; thus, including PK data in the consideration of ADRs, and stratifying analyses of drugs both by the presence, and by the direction, of PK differences greatly clarifies patterns of sex differences in ADRs. Overall, 76 of 86 drugs $(88 \%)$ had higher PK values in women than men (Tables 1 and 2), and among the 59 drugs for which ADR data were available. Of course, it remains possible that sex differences in PK parallel sex differences in ADRs independently. Ninety-six percent with higher PK values in women also induced a higher incidence of ADRs in women. For 7 drugs, male PK values exceeded those of females, but this sex difference positively predicted male-biased ADRs in only 2 of 7 instances (29\%; 4 exhibited female-biased ADRs and 1 no bias; Table 2). In the absence of any obvious reason to suspect that our sample is not representative of the more than thousands of drugs approved for human use by the FDA (US-FDA, 2019), the present data suggest that elevated drug concentrations and decreased elimination times are far more prevalent in women than men and present a quantifiable and major health risk for women.

\section{Comparison of VigiBase adverse event reporting with empirical clinical data}

For 27 of the 86 drugs surveyed, VigiBase was the only source available for data on sex differences in ADRs (Table 2). Similar to the drugs summarized in Table 1, 24 of these 27 drugs (89\%) exhibited female-biased PK values (Table 1, 52/59; Table 2, 24/27; $x^{2}=0.01, P$ > 0.9 ), among these drugs, sex-biased PKs predicted sexbiased VigiBase ADR reporting ratios (hereafter, "VB ratios") in $74 \%$ of instances (20 of 27 drugs were PK-VB ratio "concordant," Table 2). To examine how closely estimates of sex differences in ADRs inferred from VB ratios corresponded to actual sex differences in ADRs gathered from the empirical clinical literature, we calculated VB ratios for the 59 compounds in Table 1, i.e., drugs for which actual ADR information was available. This analysis indicates that sex-biased patterns of case reports in the VigiBase pharmacovigilance database correctly predict actual sex differences in ADRs in only 33 of 59 cases ( $56 \%$ of drugs were ADR-VB ratio "concordant," Table 3); concordance between ADR bias and VB ratios did not differ between drugs that had male- vs. female-biased PK values: 3 of 7 drugs (43\%) with malebiased PKs were ADR-VB ratio concordant, 30 of 52 
drugs (58\%) with female-biased PKs were ADR-VB ratio concordant; $X^{2}=0.55, P>0.4$. VigiBase indicated no sex bias in adverse event reporting (VB ratios between 0.80 and 1.20, as defined above, a "false null" error) for 15 of 26 (58\%) ADR-VB ratio discordant drugs, and a sex-biased $\mathrm{VB}$ ratio in a direction opposite to that of the actual ADR bias (e.g., a male-biased VB ratio, when real ADRs are female biased, a "false sex" error) in 11 of 26 (42\%) discordant drugs (Table 3). Pharmacovigilance databases are useful as broad indicators, but the present analysis underscores the limitations inherent in VigiBase ADRs.

\section{Discussion}

\section{PK values predict ADRs but only in women}

The present results reveal a striking sex difference in pharmacokinetics: among patients administered a standard drug dose, females are exposed to higher blood drug concentrations and longer drug elimination times than males. This likely contributes to the near doubling of adverse drug reactions in female patients, raising the possibility that women are routinely overmedicated. Whether this relation also holds for the thousands of drugs for which sex-stratified PK data are not publicly available remains to be investigated, but an affirmative answer would be consistent with our analysis. The present results also support the argument that for drugs with a sufficiently broad therapeutic index, dose reductions in women would yield a reduction in side effects.

A number of reports have identified links between sex-specific patterns of PK values, PDs, and ADRs [48, $51,55]$, but to our knowledge, the present analysis is the first to document that sex differences in PKs positively predict sex differences in ADRs broadly across multiple categories of FDA-approved pharmaceuticals. These data indicate that if a significant, female-biased PK sex difference is identified, then there is an overwhelmingly high probability that a clinically identifiable female-biased ADR will co-occur. Although it remains to be definitively established that women routinely are overmedicated, the present data are consistent with this conjecture for the drugs reviewed here, as well as for the thousands of drugs administered in equivalent doses to women and men. The intended efficacy of drugs in relation to sex remains in need of intensive investigation.

\section{Limitations}

Among the 27 drugs for which VB ratios were the only format of adverse event data, sex-biased PKs predicted sex-biased VigiBase ADR reporting ratios in $74 \%$ of instances (20 of 27 drugs were PK-VB ratio "concordant," Table 2). In all but a few instances, VigiBase contained thousands of ADR reports, but as noted above, the number of men and women treated with each drug was not specified, nor are the links between the drug and specific
ADRs known. It remains likely that some ADR sex differences in the VigiBase reflect unequal numbers of women and men treated with a given drug.

To definitively establish a cause effect relation between higher blood drug concentrations and ADRs requires concurrent measurement of PKs and ADRs in the same subjects. This has been accomplished infrequently (but see [56]).

Some have argued that what we ascribe to sex differences in the genesis of ADRs is causally related to differences in body weight. In reference to the sex difference in ADRs among patients taking zolpidem, Richardson et al. [57] stated "body weight, not sex, is the culprit." They contend that body weight eliminates the statistical significance of sex as a variable in clearance of zolpidem, referencing a study by Greenblatt et al. [58]. However, the cited paper makes no such claim, instead stating that "AUC averaged $40 \%$ to $50 \%$ higher in females than in males receiving the same dose, and the sex effect was incompletely explained by body weight". In a more recent review, Greenblatt et al. [59] note that women had on average 35\% lower apparent clearance of zolpidem than men and that this difference was not explained by body weight. They conclude instead that the pharmacodynamic effects of zolpidem are greater in women due to a combination of higher plasma concentrations and greater intrinsic sensitivity [58]. The present analysis indicates that many sex differences in ADRs persist after corrections for body weight are made.

Lastly, while we appreciate the difficulties in conducting clinical research, the standards of evidence encountered in many reports cited herein were disappointing, especially so in the clinical trials submitted to, and approved by, the FDA: reports of no statistical differences between the sexes were routinely not supported by $F$ statistics or $p$ values, and were further complicated by small sample sizes and inflated type II error. Estimates of treatment effect size were also largely absent.

\section{Recommendations}

Recommendation \#1 For all drugs currently in use, the FDA should post, on their website, PK data that were submitted as part of the drug approval process (i.e., NDAs) and associated peer reviewed publications. Generally, this information is unavailable for drugs approved prior to 2000. Once this information becomes accessible, scores if not hundreds of drugs with substantial PK sex differences will be revealed, which can facilitate corrective measures that will reduce female ADRs.

Recommendation \#2 Credible evidence of sex differences in PKs should be made available in drug labels. In popular websites directed at the public either by drug 
companies, or by sites such as WebMD, the list of adverse effects should include known sex differences.

Recommendation \#3 Almost all ADRs emerge from post-marketing reports, sometimes years after a drug appears on the market. The high correlation between elevated PKs in women and increased ADRs suggests that for drugs with higher female PKs, the initial dose should be lower for women than men and increased only if the lower dose fails to achieve the desired therapeutic effect. We anticipate this would eliminate or ameliorate many sex differences in adverse drug reactions. For orally administered drugs, pill splitting can begin to approximate a correction to the current practice where "one dose fits all." Wherever feasible, drugs should be administered on a body weight adjusted basis $(\mathrm{mg} / \mathrm{kg})$ for men as well as women.

Recommendation \#4 The FDA should require all empirical NDA data to be accompanied by documentation of statistical analyses which should meet requirements for publication in a peer-reviewed journal. Experiments reported in NDAs are less likely to be subjected to replication attempts by the scientific community, and therefore methodological or interpretive errors are less likely to be rapidly corrected by the iterative scientific process. Standards of evidence should be accordingly maintained high. At a minimum, this should include mandatory reporting of information on: a priori power analyses, measures of central tendency, variance, treatment of outlier data, statistical tests used to support statements regarding drug effects and lack thereof, specific $P$ values, corrections deployed to control type I and type II error, and post hoc estimates of treatment effect magnitude. Such information is essential if clinicians are to develop informed decisions regarding sex differences in drug effects.

Recommendation \#5 An appropriate understanding of the clinical relevance of sex-differences in drug treatment should be part of the board certification process for healthcare providers and reinforced in continuing medical education courses.

Recommendation \#6 Establishing sex parity in the drug approval process should be explicitly identified as a long-term goal of the Department of Health and Human Services. The decades-long pattern of neglect of female animals in preclinical research and underrepresentation of women in clinical trials and research must be corrected, and the recent $\mathrm{NIH}$ oversight and vigilance must be maintained.
Recommendation \#7 Pharmaceutical companies should pay more attention, beginning in the early drug development phases to sex-appropriate dosing [60]. Drug development commonly begins with pre-clinical modelling, in vitro experiments, and in vivo studies in mouse models. Recent analyses indicate that the overwhelming majority of basic research in mammalian physiology and pharmacology is based on work in male animals [6]. If, during the early stages of pre-clinical development, a compound is titrated or optimized specifically in male cells or in male mice, then any sex biases inherent in such models may be passed forward into later stages of drug development. The disproportionate expression of increased PKs and ADRs in women may be one result of this continued neglect.

\section{Perspectives and significance}

The substantially elevated incidence of adverse drug reactions in women is undisputed, but the biological basis for this sex difference is poorly understood. The present study tested the hypothesis that sex differences in pharmacokinetics contributes to the female sex bias in adverse drug reactions. The analyses indicate that for many drugs administration of the same standard drug dose to women and men results in higher blood concentrations and/or longer elimination times in women and that these female-biased pharmacokinetics are a striking predictor of adverse drug reactions in women. Pharmaceutical pipelines that optimize drugs using males in vitro (male cells) and in vivo (male preclinical animal models) may contribute to the prevalence of these PKADR relations. Pervasive unintended and adverse drug responses may reflect routine overmedication of women for many drugs. Measures to ameliorate the sex difference in adverse drug reactions include reducing drug doses for women.

\section{Supplementary information}

Supplementary information accompanies this paper at https://doi.org/10. 1186/s13293-020-00308-5.

Additional file 1: Supplementary Results.

Acknowledgements

We are grateful to Annaliese Beery, Alison Fleming, David Greenblatt, Gary Kraemer, Lance Kriegsfeld, and Ellen Zucker for constructive criticism and helpful suggestions.

\section{Authors' contributions}

BJP and IZ collected and analyzed the data; BJP and IZ approved the manuscript. IZ conceived of the study; IZ and BJP participated in study design and coordination; $I Z$ and BJP wrote the manuscript.

Funding

The authors received no funding to perform this work. 


\section{Availability of data and materials}

The datasets used and/or analyzed during the current study are available from either author and described in Additional file 1.

\section{Ethics approval and consent to participate}

Not applicable

\section{Consent for publication}

Not applicable.

\section{Competing interests}

The authors declare that they have no competing interests.

\section{Author details}

${ }^{1}$ Department of Psychology, University of California, Berkeley, 2121 Berkeley Way West, Berkeley, CA 94720, USA. ²Department of Integrative Biology, University of California, Berkeley, 3040 VLSB, Berkeley, CA 94720, USA. ${ }^{3}$ Department of Psychology and Committee on Neurobiology, University of Chicago, Chicago, IL 60637, USA

\section{Received: 24 March 2020 Accepted: 18 May 2020}

Published online: 05 June 2020

\section{References}

1. Klinge I. Gender perspectives in European research. Pharmacol Res. 2008; 58(3-4):183-9.

2. Wetherington $\mathrm{CL}$. Sex-gender differences in drug abuse: a shift in the burden of proof? Exp Clin Psychopharmacol. 2007;15(5):411-7.

3. Rogers WA, Ballantyne AJ. Exclusion of women from clinical research: myth or reality? Mayo Clin Proc. 2008;83(5):536-42.

4. Soldin OP, Mattison DR. Sex differences in pharmacokinetics and pharmacodynamics. Clin Pharmacokinet. 2009;48(3):143-57.

5. Hayes SN, Redberg RF. Dispelling the myths: calling for sex-specific reporting of trial results. Mayo Clin Proc. 2008;83:523-5.

6. Beery AK, Zucker I. Sex bias in neuroscience and biomedical research. Neurosci Biobehav Rev. 2011;35(3):565-72.

7. Geller SE, Koch AR, Roesch P, Filut A, Hallgren E, Carnes M. The more things change, the more they stay the same: a study to evaluate compliance with inclusion and assessment of women and minorities in randomized controlled trials. Acad Med. 2018;93(4):630-5.

8. Zucker I, Beery AK. Males still dominate animal studies. Nature. 2010; 465(7299):690.

9. Karlsson Lind L, von Euler M, Korkmaz S, Schenck-Gustafsson K. Sex differences in drugs: the development of a comprehensive knowledge base to improve gender awareness prescribing. Biol Sex Differ. 2017;8(1):32.

10. Fadiran $\mathrm{EO}$, Zhang L. Effects of sex differences in the pharmacokinetics of drugs and their impact on the safety of medicines in women. In: HarrisonWoolrych M, editor. Medicines for women. Cham: Springer International Publishing; 2015. p. 41-68

11. Fisher JA, Ronald LM. Sex, gender, and pharmaceutical politics: from drug development to marketing. Gend Med. 2010;7(4):357-70.

12. WHO. http://www.vigiaccess.org.

13. WHO. http://who-umc.org/vigibase/vigibase/.

14. Tharpe N. Adverse drug reactions in women's health care. J Midwifery Womens Health. 2011:56(3):205-13.

15. Nakagawa K, Kajiwara A. Female sex as a risk factor for adverse drug reactions. Nihon Rinsho. 2015:73(4):581-5.

16. Damien S, Patural H, Trombert-Paviot B, Beyens M-N. Adverse drug reactions in children: 10 years of pharmacovigilance. Arch Pediatr. 2016:23(5):468-76.

17. Yu Y, Chen J, Li D, Wang L, Wang W, Liu H. Systematic analysis of adverse event reports for sex differences in adverse drug events. Sci Rep. 2016;6(1): 24955.

18. Martin RM, Biswas PN, Freemantle SN, Pearce GL, Mann RD. Age and sex distribution of suspected adverse drug reactions to newly marketed drugs in general practice in England: analysis of 48 cohort studies. Br J Clin Pharmacol. 1998:46(5):505-11.

19. Manteuffel M, Williams S, Chen W, Verbrugge RR, Pittman DG, Steinkellner A Influence of patient sex and gender on medication use, adherence, and prescribing alignment with guidelines. J Women's Heal. 2014;23(2):112-9.
20. Holford NHG, Sheiner LB. Understanding the dose-effect relationship: clinical application of pharmacokinetic-pharmacodynamic models. Clin Pharmacokinet. 1981;6(6):429-53.

21. Meibohm B, Beierle I, Derendorf H. How important are gender differences in pharmacokinetics?: Clin Pharmacokinet. 2002;41(5):329-42.

22. Harris RZ, Benet LZ. Schwartz JB. Gender effects in pharmacokinetics and pharmacodynamics: Drugs. 1995;50(2):222-39.

23. Gandhi M, Aweeka F, Greenblatt RM, Blaschke TF. Sex differences in pharmacokinetics and pharmacodynamics. Annu Rev Pharmacol Toxicol. 2004;44:499-523.

24. Kando JC, Yonkers KA. Cole JO. Gender as a risk factor for adverse events to medications: Drugs. 1995;50(1):1-6.

25. Beierle I, Meibohm B, Derendorf H. Gender differences in pharmacokinetics and pharmacodynamics. Int J Clin Pharmacol Ther. 1999;37(11):529-47.

26. Cotreau MM, von Moltke LL, Greenblatt DJ. The influence of age and sex on the clearance of cytochrome P450 3A substrates. Clin Pharmacokinet. 2005; 44(1):33-60.

27. Greenblatt DJ, von Moltke LL. Gender has a small but statistically significant effect on clearance of CYP3A substrate drugs. J Clin Pharmacol. 2008;48(11): 1350-5.

28. Anderson GD. Chapter 1 gender differences in pharmacological response. In: International review of neurobiology. Elsevier; 2008. p. 1-10.

29. Islam MM, Iqbal U, Walther BA, Nquyen P-A, Li Y-C, Dubey NK, et al. Genderbased personalized pharmacotherapy: a systematic review. Arch Gynecol Obstet. 2017;295(6):1305-17.

30. Brambilla DJ, O'Donnell AB, Matsumoto AM, McKinlay JB. Intraindividual variation in levels of serum testosterone and other reproductive and adrenal hormones in men. Clin Endocrinol. 2007:67(6):853-62.

31. Petros S. Lepirudin in the management of patients with heparin-induced thrombocytopenia. Biologics. 2008;2(3):481-90.

32. Abdel-Rahman AA. Influence of sex on cardiovascular drug responses: role of estrogen. Curr Opin Pharmacol. 2017:33:1-5.

33. Warkentin TE, Sheppard J-Al, Sigouin CS, Kohlmann T, Eichler P, Greinacher A. Gender imbalance and risk factor interactions in heparin-induced thrombocytopenia. Blood. 2006;108(9):2937-41.

34. Arpon DR, Gandhi MK, Martin JH. A new frontier in haematology combining pharmacokinetic with pharmacodynamic factors to improve choice and dose of drug. Br J Clin Pharmacol. 2014;78(2):274-81.

35. Zopf Y, Rabe C, Neubert A, Hahn EG, Dormann H. Risk factors associated with adverse drug reactions following hospital admission: a prospective analysis of 907 patients in two German university hospitals. Drug Saf. 2008; 31(9):789-98.

36. Vree TB, Dammers E, Valducci R. Sex-related differences in the pharmacokinetics of isosorbide-5-mononitrate $(60 \mathrm{mg})$ after repeated oral administration of two different original prolonged release formulations. Int Clin Pharmacol Ther. 2004;42(8):463-72

37. Schwartz JB. The influence of sex on pharmacokinetics: Clin Pharmacokinet. 2003;42(2):107-21

38. Franconi F, Campesi I. Sex impact on biomarkers, pharmacokinetics and pharmacodynamics. Curr Med Chem. 2017;24(24).

39. Schwartz JB. The current state of knowledge on age, sex, and their interactions on clinical pharmacology. Clin Pharmacol Ther. 2007:82(1):8796.

40. Franconi F, Campesi I. Pharmacogenomics, pharmacokinetics and pharmacodynamics: interaction with biological differences between men and women: Pharmacological differences between sexes. Br J Pharmacol. 2014;171(3):580-94

41. Amacher DE. Female gender as a susceptibility factor for drug-induced liver injury. Hum Exp Toxicol. 2014;33(9):928-39.

42. Institute of Medicine. Committee on Understanding the Biology of Sex and Gender Differences. Exploring the biological contributions to human health. Does sex matter? 2001.

43. Chen M. Pharmacokinetic analysis of bioequivalence trials: implications for sex-related issues in clinical pharmacology and biopharmaceutics. Clin Pharmacol Ther. 2000;68(5):510-21.

44. Fife DJ, Maibach HI. Gender differences in the pharmacokinetics of oral dermatologic medications. J Toxicol Cutan Ocul Toxicol. 2005;23(2):119-33.

45. Polasek TM, Shakib S, Rostami-Hodjegan A. Precision dosing in clinical medicine: present and future. Expert Rev Clin Pharmacol. 2018;11:743-6.

46. Panetta JA Srinivasan U Gender based medicine In: Annual reports in medicinal chemistry. Elsevier; 1998. p. 355-63. 
47. Duan JZ. Applications of population pharmacokinetics in current drug labelling. J Clin Pharm Ther. 2007;32(1):57-79.

48. Tamargo J, Rosano G, Walther T, Duarte J, Niessner A, Kaski J, et al. Gender differences in the effects of cardiovascular drugs. Eur Hear J - Cardiovasc Pharmacother. 2017 Oct;3(3):163-82.

49. Regitz-Zagrosek V, Kararigas G. Mechanistic pathways of sex differences in cardiovascular disease. Physiol Rev. 2017;97:1-37.

50. Crawford MB. DeLisi LE. Issues related to sex differences in antipsychotic treatment: Curr Opin Psychiatry. 2016;29(3):211-7.

51. Salzano A, Demelo-Rodriguez P, Marra AM, Proietti M. A focused review of gender differences in antithrombotic therapy. Curr Med Chem. 2017;24(24).

52. Ofotokun I, Chuck SK, Hitti JE. Antiretroviral pharmacokinetic profile: a review of sex differences. Gend Med. 2007:4(2):106-19.

53. Sramek JJ, Murphy MF, Cutler NR. Sex differences in the psychopharmacological treatment of depression. Dialogues Clin Neurosci. 2016;18(4):11.

54. FDA. https://www.accessdata.fda.gov/scripts/cder/daf/.

55. Humphries KH, Izadnegahdar M, Sedlak T, Saw J, Johnston N, SchenckGustafsson K, et al. Sex differences in cardiovascular disease - impact on care and outcomes. Front Neuroendocrinol. 2017;46:46-70.

56. Greenblatt DJ, Legangneux E, Harmatz JS, Weinling E, Freeman J, Rice K, et al. Dynamics and kinetics of a modified-release formulation of zolpidem: comparison with immediate-release standard zolpidem and placebo. J Clin Pharmacol. 2006;46(12):1469-80.

57. Richardson SS, Reiches M, Shattuck-Heidorn H, LaBonte ML, Consoli T. Opinion: focus on preclinical sex differences will not address women's and men's health disparities. Proc Natl Acad Sci. 2015;112(44):13419-20.

58. Greenblatt DJ, Harmatz JS, Singh NN, Steinberg F, Roth T, Moline ML, et al. Gender differences in pharmacokinetics and pharmacodynamics of zolpidem following sublingual administration: J Clin Pharmacol. 2014;54(3): 282-90.

59. Greenblatt DJ, Harmatz JS, Roth T. Zolpidem and gender: are women really at risk? J Clin Psychopharmacol. 2019;39(3):189-99.

60. Colombo D, Banfi G, Cassano N, Graziottin A, Vena GA, et al. The GENDER ATTENTION observational study: gender and hormonal status differences in the incidence of adverse events during cyclosporine treatment in psoriatic patients. Adv Ther. 2017;34(6):1349-63.

\section{Publisher's Note}

Springer Nature remains neutral with regard to jurisdictional claims in published maps and institutional affiliations.

Ready to submit your research? Choose BMC and benefit from:

- fast, convenient online submission

- thorough peer review by experienced researchers in your field

- rapid publication on acceptance

- support for research data, including large and complex data types

- gold Open Access which fosters wider collaboration and increased citations

- maximum visibility for your research: over $100 \mathrm{M}$ website views per year

At $\mathrm{BMC}$, research is always in progress.

Learn more biomedcentral.com/submissions 